$$
\begin{array}{r}
1 N=39 \\
1 / 6436
\end{array}
$$

NASA Technical Memorandum 105726

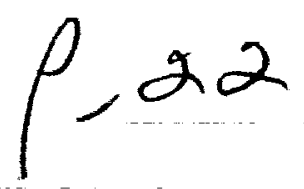

\title{
A Differential CDM Model for Fatigue of Unidirectional Metal Matrix Composites
}

S.M. Arnold

Lewis Research Center

Cleveland, Ohio

and

S. Kruch

ONERA

92322 Chatillon, France

Prepared for the

American Society of Mechanical Engineers

Anaheim, California, November 8-13, 1992
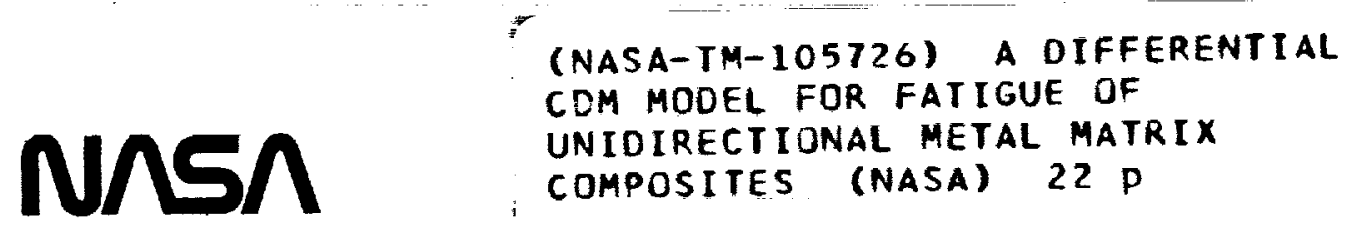

N92-31505

Unclas 


\title{
A DIFFERENTIAL CDM MODEL FOR FATIGUE OF UNIDIRECTIONAL METÁL MATRIX COMPOSITES
}

\author{
By \\ S. M. Arnold \\ National Aeronautics and Space Administration \\ Lewis Research Center Cleveland, Ohio $\mathbf{4 4 1 3 5}$ \\ and \\ S. Kruch \\ Office Nationale d'Etudes et de Recherches Aerospatiales \\ 92322 Chatillon, France.
}

\begin{abstract}
A multiaxial, isothermal, continuum damage mechanics model for fatigue of a unidirectional metal matrix composite volume element is presented. The model is phenomenological, stress based, and assumes a single scalar internal damage variable, the evolution of which is anisotropic. The development of the fatigue damage model, (i.e., evolutionary law) is based on the definition of an initially transversely isotropic fatigue limit surface, a static fracture surface, and a normalized stress amplitude function. The anisotropy of these surfaces and function, and therefore the model, is defined through physically meaningful invariants reflecting the local stress and material orientation. This transversely isotropic model is shown, when taken to it's isotropic limit, to directly simplify to a previously developed and validated isotropic fatigue continuum damage model.

Results of a nondimensional parametric study illustrate (1) the flexibility of the present formulation in attempting to characterize a class of composite materials and (2) the capability of the formulation in predicting anticipated qualitative trends in the fatigue behavior of unidirectional metal matrix composites. Also, specific material parameters representing an initial characterization of the composite system SiC/Ti $15-3$ and the matrix material $(\mathrm{Ti} 15-3)$ are reported.
\end{abstract}

\section{NOMENCLATURE}

$\begin{array}{cl}\frac{\text { Stresses }}{\sigma_{\mathrm{ij}}} & \text { Cauchy stress tensor } \\ \mathrm{S}_{\mathrm{ij}} & \text { deviatoric stress tensor } \\ \mathrm{S}_{\max } & \text { normalized uniaxial maximum stress } \\ \mathbf{S} & \text { normalized uniaxial mean stress } \\ \sigma_{\max } & \text { uniaxial maximum stress } \\ \bar{\sigma} & \text { uniaxial mean stress }\end{array}$




\section{Invariants}

$\mathrm{J}_{2} \quad$ second invariant of the deviatoric stress (expressed for shear)

$\mathrm{I}_{1} \quad$ invariant representing transverse shear stress

$I_{2} \quad$ invariant representing longitudinal shear stress

$I_{3}$ invariant representing maximum normal stress in the fiber direction

\section{Material Parameters}

$\sigma_{u}$ is the ultimate normal stress or static fracture stress

$\sigma_{\mathrm{f} \ell} \quad$ normal stress endurance limit

$a$ ratio of endurance limit to static fracture stress; $\sigma_{\mathrm{fl}} / \sigma_{\mathrm{u}}$

M normalizing stress amplitude constant

$\mathscr{K}$ ratio of stress amplitude constant to static fracture stress; $\mathrm{M} / \sigma_{\mathrm{u}}$

$\omega_{u} \quad$ ratio of longitudinal to transverse ultimate normal stress

$\omega_{f \ell}$ ratio of longitudinal to transverse normal fatigue or endurance limit stress

$\omega_{\mathrm{m}}$ ratio of longitudinal to transverse normalizing normal stress amplitude

$\eta_{u} \quad$ ratio of longitudinal to transverse shear static fracture stress

$\eta_{f \ell}$ ratio of longitudinal to transverse shear fatigue limit stress

$\eta_{\mathrm{m}} \quad$ ratio of longitudinal to transverse shear normalizing stress amplitude

a scaling factor for stress dependency in the fatigue damage exponent

$b, b^{\prime}$ parameters indicating effect of mean stress

$\alpha$ fatigue damage variable exponent (can be a function of stress)

$\beta$ exponent on the normalized stress amplitude

$\theta$ angle between fibers and coordinate axis

\section{Subscripts}

( ) longitudinal propertiès

( ) T $_{\mathrm{T}}$ transverse properties

o initial value

\section{Miscellaneous}

$d_{i} \quad$ unit vector denoting local fiber direction

$D_{i j} \quad$ second order direction tensor; $d_{i} d_{j}$

$\delta_{i j} \quad$ Kronecker delta function

$\mathrm{D}_{\mathrm{F}}$ fatigue damage variable (measure)

$\hat{\mathrm{F}}_{\mathrm{f} \ell}$ fatigue limit surface

$\hat{\mathrm{F}}_{u} \quad$ static fracture surface

$\hat{\mathrm{F}}_{\mathrm{m}} \quad$ normalized stress amplitude function

$\mathrm{P}$ combined hydrostatic mean stress measure

$\zeta$ parameter in $P$ weighting the influence of the maximum hydrostatic stress

N number of cycles

$\mathrm{N}_{\mathrm{F}}$ number of cycles to failure

$<>$ Macauley brackets 


\section{INTRODUCTION}

In recent years, because of advances in scanning electron microscopy, acoustic emission techniques, and other nondestructive testing methods, a consensus has emerged that the nonlinear response of solids and ultimately their mechanical strength are dependent not only on the basic structure of the material but also on the type, distribution, size, and orientation of the defects in its structure. As a result, a relatively new branch of continuum mechanics, known as Continuum Damage Mechanics (CDM), has emerged. Continuum mechanics allows one to describe (over an appropriate representative volume element) the heterogeneous microprocesses involved during the straining of materials and structures at the macroscale. Similarly, CDM allows one to describe the material's progressive deterioration (damage) from the virgin state (no damage) to the final state, corresponding generally to macrocrack initiation and propagation (or the "breaking up" of the representative volume element). Consequently, the life-limiting macroscopic properties such as rupture strength, fatigue life, or creep rupture lifetime of the material can be predicted.

The tracking, or description, of the evolution of damage is accomplished by the introducing special thermodynamic (internal) field variables representing, in an appropriate statistical sense, the local distribution and density of defects. Numerous damage theories, both micromechanical $[1-6]$ and phenomenological [7-11], have been proposed and discussed in the literature. There is great diversity in the mathematical nature of the damage variable(s) (e.g., scalar $[7,12,13]$, vectors $[14,15]$ and tensors $[12,16,17])$, and thus the damage theories; this stems from the difficulty in directly measuring "damage" macroscopically and the degree of approximation with which the internal variables describe the salient aspects of the macroscopic effects of the microdefect kinematics. For a number of excellent review articles and books on this subject see references $[7,12,18-24]$.

In this paper a phenomenological, isothermal, transversely isotropic, fatigue CDM model, with a scalar damage internal variable, applicable to unidirectional metallic composites, will be described. The present model is an extension of a previously validated CDM model developed at ONERA (Office Nationale d'Etudes et de Recherches Aerospatiales) $[10,11,18,19,25,26,27,28]$ for isotropic monolithic metals. A brief review of the CDM work of Chaboche and his colleagues at ONERA is given in reference [29]; it provides a foundation for the present extension of the ONERA models to transversely isotropic materials (e.g., hexagonally packed metal matrix composites).

\section{A CDM FATIGUE MODEL FOR INITIALIY ANISOTROPIC MATERIALS}

Different damage variables are associated with different damage processes, such as creep, fatigue, ductile, and brittle damage, and have been discussed in the literature extensively. Here we will confine ourselves to the modeling of fatigue damage by using a scalar damage measure. Figure 1 clearly illustrates the particular damage mechanisms considered in this study of the fatigue of monolithic metals. In Fig. 1, the fatigue crack initiation and growth process is illustrated schematically; the damage $\left(D_{F}\right)$ is associated, macroscopically, with the initiation and propagation of transgranular defects (e.g., slip bands and microcracks). The possible equivalence between the definition of $D_{F}$ by the effective stress concept, the definition of $D_{F}$ in terms of the remaining life concept, and the quantification of physical damage in terms of micro-cracking has been shown by microcrack measurements made by Cailletaud and Levaillant [30], Hua and Socie [31], and Socie et al. [32].

The Continuum Damage Mechanics approach, which supports the previously described global measure of fatigue damage in monolithic isotropic materials, presents two theoretical deficiencies which make it inconsistent with a continuum approach the surface character of fatigue damage and (2) the small number of large defects present during the propagation stage. Interestingly enough however, these deficiencies do not appear to affect its ability to correctly describe many experimental results (performed under uniaxial loading) in terms of cumulative fatigue damage. 

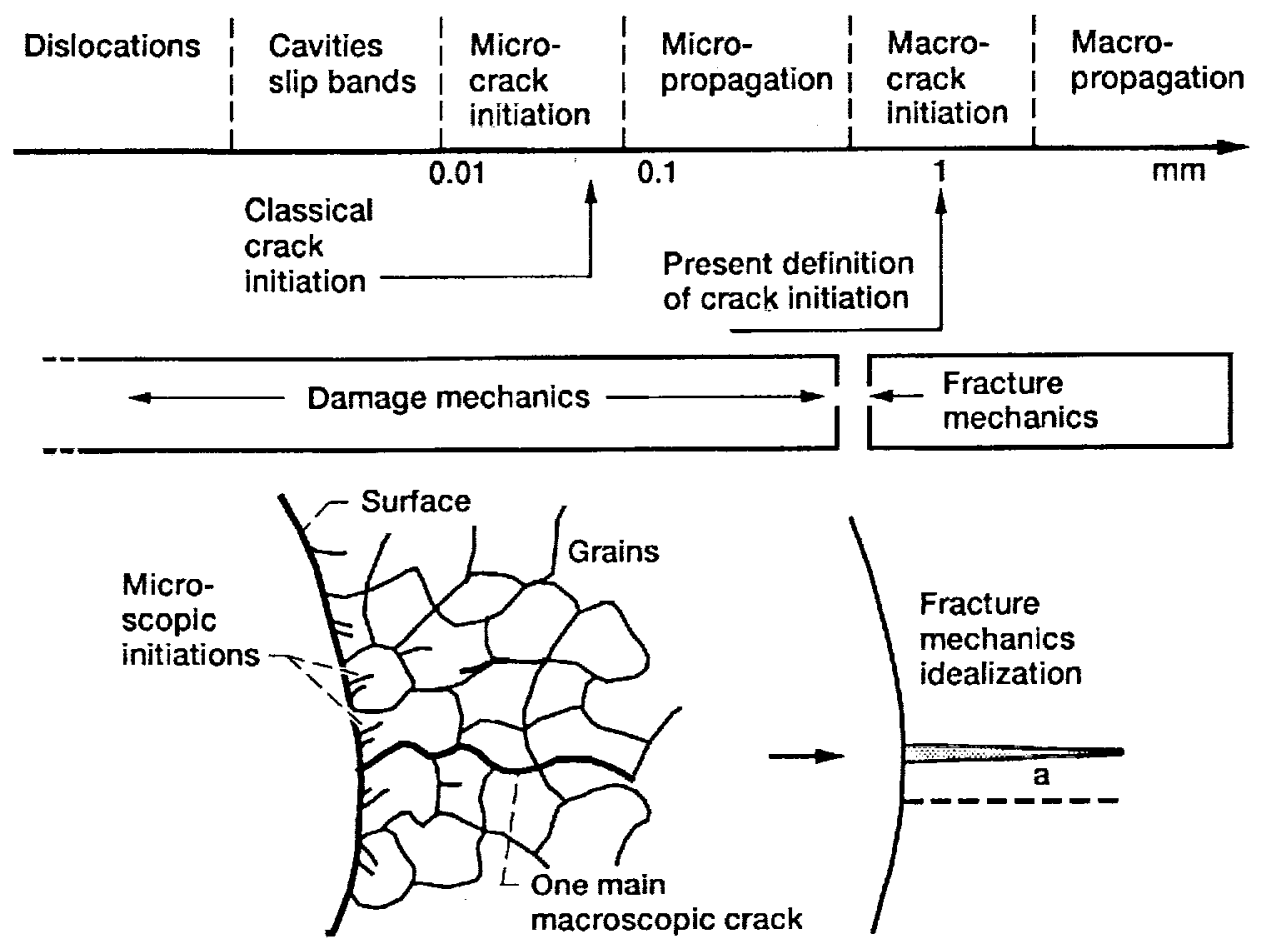

Fatigue damage: nucleation of slip bands, microcracks, and transgranular defects

Figure 1.-Different damage modes and the associated scale in a monolithic metal.

We believe that these two theoretical deficiencies can be removed by establishing a representative volume element (RVE) on the mesostructural scale of a composite material; then the surface character of fatigue will transfer to the interface region of each constituent (or phase), and the number of large defects occurring during the propagation period will similarly increase. This hypothesis was borne out by observation of experiments conducted under specific thermal and mechanical loading histories $[33,34]$. There are, however, a number of surface and environmental effects which will not necessarily transfer to the fibers, for example those effects that are associated with oxidation in the $\mathrm{SiC} / \mathrm{Ti}$ 15-3 system [35]. A nonrigorous definition of an RVE for a given composite material is given in Fig. 2. In short it requires that the RVE include a sufficient number of unit cells to allow (statistically) the heterogeneous nature of the material to be homogenized.

Figure 3 is the extension of Fig. 1 to the mesoscale; it illustrates the mesostructural damage (i.e., the microcracks and mesocracks) that might result when a composite material is subjected to fatigue loading. Here, damage mechanisms similar to those on the microstructural scale are postulated to occur on the mesostructural scale; the surface or interface of a constituent (the fiber) plays the role (on the mesostructural scale) of the grain boundary of a constituent (grain) on the microscopic scale.

Furthermore, because of the internal structure of the material, a sufficient number of defects will be present, thus allowing a theoretically consistent continuum representation of fatigue damage to be constructed.

In addition to matrix cracking and the formation of microcracks around the fibers, other damage modes must be included, such as fiber breaking, fiber/matrix debonding, and interlaminar cracking. It has been noted that damage occurs in the form of different multiple cracking modes and that there is no isolated single crack that dominates the development of damage. Similarly in composite laminates, damage develops along preferred orientations; for example, matrix cracks in off-axis plies typically are channeled by the fibers in those plies and interlaminar planar cracks grow along fibers in the neighboring plies [36]. 


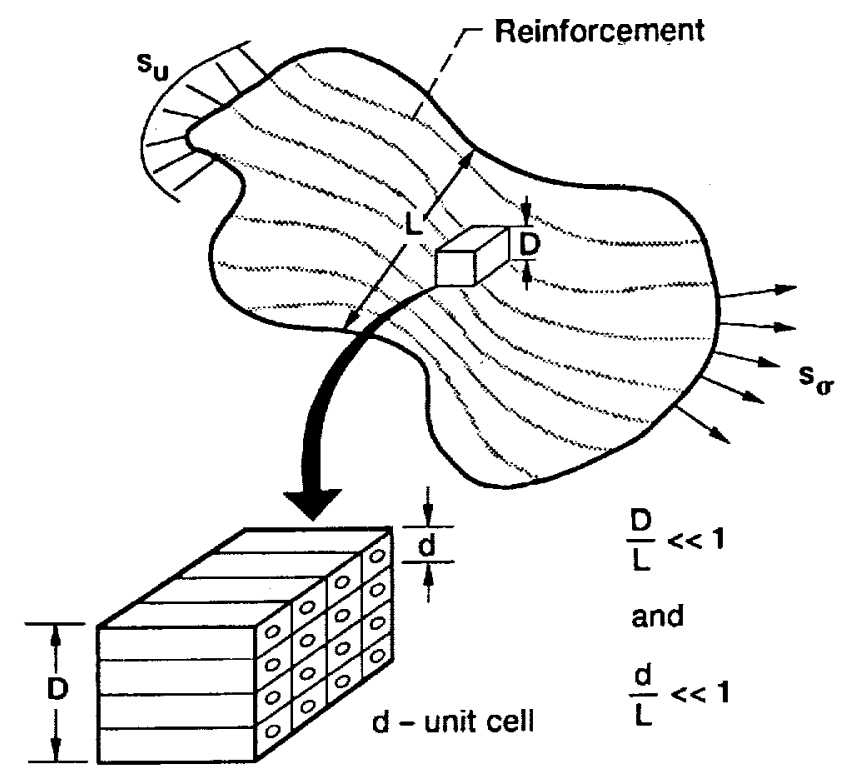

Figure 2.-Nonrigorous definition of representative volume element (RVE); $s_{u}=$ displacement field, $s_{\sigma}=$ stress field.
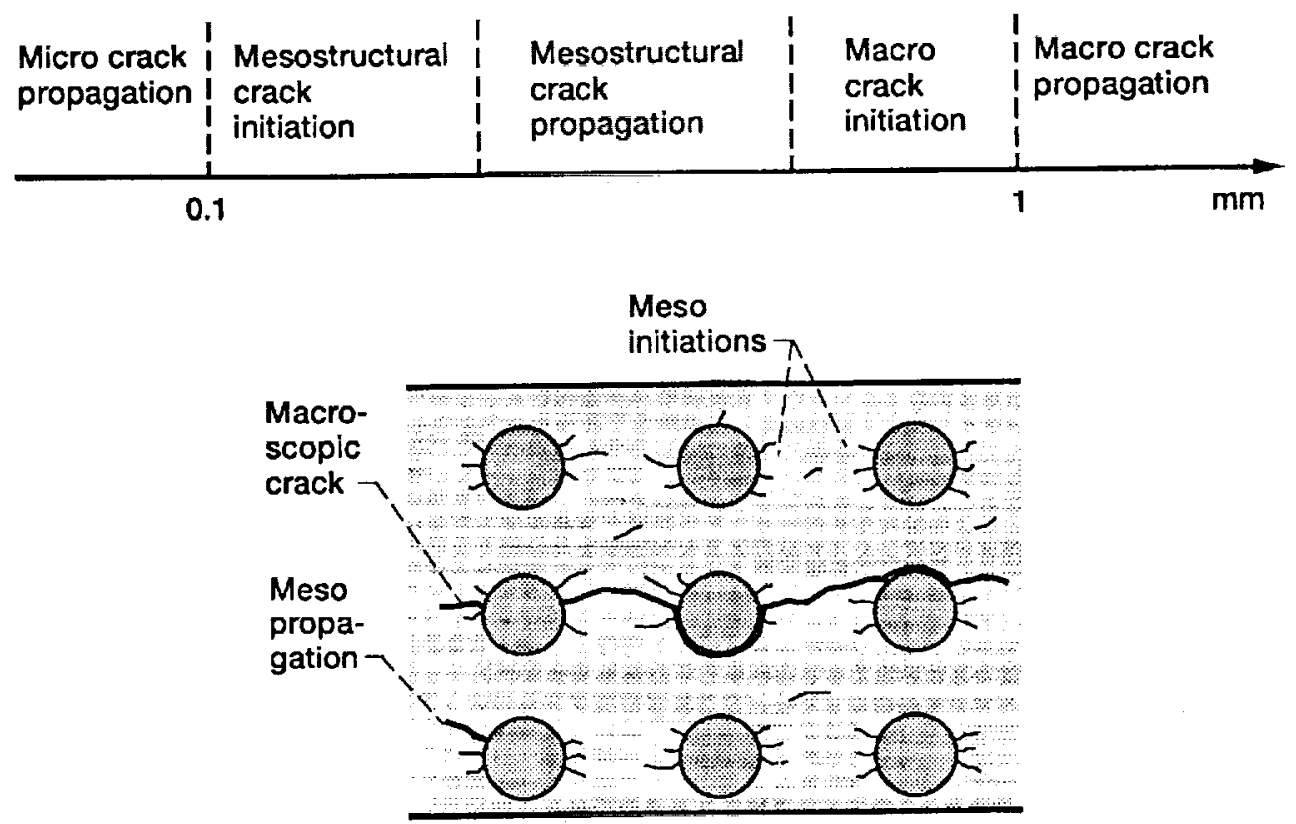

Fatigue damage: initiation and propagation of transgranular defects.

Figure 3.-Different damage modes and the associated scale in a metallic composite. Fibers on mesostructural scale are analogous to grain boundaries on microstructural scale.

These direction-oriented damage modes suggest the need for a direction-dependent damage variable (e.g., a vector or tensor). Here, however, on the basis of the strong initial anisotropy of the composite, we assumed that the damage measure is a scalar, with the evolution of damage being anisotropic and associated with the preferred direction 
of the material. For example, if the composite is loaded in the fiber direction, the evolution of damage would be small relative to the case in which the composite is loaded normal to the fiber. However, because of the assumed scalar measure, the distribution of damage would be identical in all directions. Thus the accumulation but not the magnitude of damage is direction dependent. The approach taken to model this damage was the stress based approach detailed in references [12] and [29], wherein the definition of effective stress and the concept of remaining life were utilized to measure and interpret damage.

\section{Multiaxial Statement}

The ONERA model was extended by introducing anisotropic damage surfaces with appropriate stress invariants [37-39] representing stress states that are likely to strongly influence the various damage modes in metallic composites. For instance, we assumed (1) that the transverse shear stress $\left(\mathrm{I}_{1}\right)$ and thus implicitly the transverse normal stress, dictates matrix cracking; (2) that the longitudinal shear stress $\left(\mathrm{I}_{2}\right)$ dictates interfacial degradation; and (3) that the maximum normal stress $\left(I_{3}\right)$ in the fiber direction dictates fiber breakage. In this way, we believe that the following fatigue limit and static fracture surfaces and the normalized stress amplitude function contain the most pertinent damage-producing stress measures. Let

$$
F_{()}=\sqrt{\frac{1}{()_{L}^{2}\left[\left(4 \omega_{(}^{2}-1\right) I_{1}+\frac{\left.\left(4 \omega_{(}^{2}\right)^{-1}\right)}{\left.\eta_{(}^{2}\right)} I_{2}+\frac{{ }^{9}}{4} I_{3}\right]}}
$$

where the fatigue limit surface ${ }^{1}$ is defined as

$$
\hat{\mathrm{F}}_{\mathrm{f} \ell}-1=\frac{1}{2} \max _{\mathrm{t}} \max _{\mathrm{t}_{0}} \mathrm{~F}_{(\mathrm{f} \ell)}\left[\sigma_{\mathrm{ij}}(\mathrm{t})-\sigma_{\mathrm{ij}}\left(\mathrm{t}_{0}\right)\right]-1
$$

the static fracture surface is

$$
1-\hat{F}_{u}=1-\max _{t} F_{(u)}\left[\sigma_{i j}(t)\right]
$$

and the normalized stress amplitude is;

$$
\hat{\mathrm{F}}_{\mathrm{m}}=\hat{\mathrm{F}}_{\mathrm{m}}\left(\sigma_{\mathrm{ij}}\right)=\frac{1}{2} \max _{\mathrm{t}} \max _{\mathrm{t}_{0}}\left\{\mathrm{~F}(\mathrm{~m})\left[\sigma_{\mathrm{ij}}(\mathrm{t})-\sigma_{\mathrm{ij}}\left(\mathrm{t}_{0}\right)\right]\right\}
$$

The subscript ( ) in Eq.(1) is to be replaced by either fl, $u$, or $m$. Material parameters (some of them varying with the mean stress) that describe the initial anisotropy of the surfaces are defined as follows:

$$
\begin{aligned}
& \mathrm{fl}_{\mathrm{L}}=\sigma_{\mathrm{f} \ell_{\mathrm{L}}} ; \\
& \mathrm{m}_{\mathrm{L}}=\mathrm{M}_{\mathrm{L}} \\
& \eta_{\mathrm{f} \ell}=\tau_{\mathrm{f} \ell_{\mathrm{L}}} / \tau_{\mathrm{fl}} ; \\
& \eta_{\mathrm{m}}=\tau_{\mathrm{m}_{\mathrm{L}}} / \tau_{\mathrm{m}_{\mathrm{T}}} ; \\
& \mathrm{u}_{\mathrm{L}}=\sigma_{\mathrm{u}_{\mathrm{L}}} \text {; } \\
& \omega_{\mathrm{f} \ell}=\mathrm{f} \ell_{\mathrm{L}} / \mathrm{f} \ell_{\mathrm{T}} ; \\
& \omega_{\mathrm{m}}=\mathrm{M}_{\mathrm{L}} / \mathrm{M}_{\mathrm{T}} \text {; } \\
& \eta_{\mathrm{u}}=\tau_{\mathbf{u}_{\mathrm{L}}} / \tau_{\mathbf{u}_{\mathrm{T}}} \text {; } \\
& w_{\mathrm{u}}=\mathrm{u}_{\mathrm{L}} / \mathbf{u}_{\mathrm{T}}
\end{aligned}
$$

The authors acknowledge that not all monolithic materials exhibit a marked fatigue or endurance limit (e.g., nonferrous alloys); however we assume (on the basis of experimental evidence [40]) that a sufficiently large class of composite materials will possess such a limit. Furthermore, we assert that fatigue lives beyond some specified value, say $10^{7}$, can be considered infinite for most practical design purposes and thereby allow the assumption of an endurance limit. 
Note that the subscripts $L$ and $T$ denote, respectively, the longitudinal (along the fiber) and transverse (normal to the fiber) directions.

The physically meaningful invariants $I_{1}, I_{2}$, and $I_{3}$, respectively, are defined as (cf. $[39,41])$

$$
\begin{array}{ll}
\mathrm{I}_{1} & =\mathrm{J}_{2}-\hat{\mathrm{I}}+\frac{1}{4} \mathrm{I}_{3} \\
\mathrm{I}_{2} & =\hat{\mathrm{I}}-\mathrm{I}_{3} \\
\mathrm{I}_{3} & =\mathrm{I}^{2}
\end{array}
$$

in which

$$
\begin{array}{ll}
J_{2} & =\frac{1}{2} S_{i j} S_{i j} \\
I & =D_{i j} S_{i j} \\
\hat{I} & =D_{i j} S_{j k} S_{k i} \\
D_{i j} & =d_{i j} \\
S_{i j} & =\sigma_{i j}-\frac{1}{3} \sigma_{k k} \delta_{i j}
\end{array}
$$

and $d_{i}(i=1,2,3)$ represents the components of a unit vector denoting the local fiber direction.

Now, from the fatigue limit and static fracture surfaces and normalized stress amplitude function we can formulate the multiaxial representation of the extended fatigue damage evolutionary law; this is valid for materials that possess initial transversely isotropic material symmetry (e.g., hexagonally packed unidirectional composite materials):

$$
\mathrm{dD}_{\mathrm{F}}=\left[1-\left(1-\mathrm{D}_{\mathrm{F}}\right)^{\beta+1}\right]^{\alpha}\left[\frac{\hat{\mathrm{F}}_{\mathrm{m}}}{\left(1-\bar{D}_{\mathrm{F}}\right)}\right]^{\beta} \mathrm{dN}
$$

$$
\text { with } \quad \alpha=1-a \frac{<\dot{\mathrm{F}}_{\mathrm{f \ell}}-1>}{<1-\hat{\mathrm{F}}_{\mathrm{u}}>}
$$

and

$$
\begin{aligned}
& \sigma_{\mathrm{f} \ell_{\mathrm{L}}}=\sigma_{\mathrm{f} \ell_{\mathrm{L}}}(0)\left(1-3 \mathrm{~b}^{\prime} \mathrm{P}\right) \\
& \mathrm{M}_{\mathrm{L}}=\mathrm{M}_{0_{\mathrm{L}}}(1-3 \mathrm{~b} \mathrm{P})
\end{aligned}
$$

where $a, b, b$, $\beta, \quad \sigma_{f \ell_{L}}(0), \sigma_{u_{L}}, M_{0}$ are material constants and henceforth,

$$
<\mathrm{X}> \begin{cases}=0, & \mathrm{X}<0 \\ =\mathrm{X}, & \mathrm{X} \geq 0\end{cases}
$$

defines the Macauley bracket.

One additional modification, besides the inclusion of a preferred direction, has been introduced into the preceding fatigue damage model: a hydrostatic stress measure $P$ that combines both the Sines [42] and Crossland [43] criteria, that is,

$$
\mathrm{P}=\zeta \sigma_{\mathrm{Hmax}}+(1-\zeta) \sigma_{\text {Havg. }}
$$


where

$$
\begin{aligned}
\sigma_{\text {Havg }} & =\frac{1}{2}\left\{\max _{t}\left[\sigma_{\mathrm{ii}}(t)\right]+\min _{t}\left[\sigma_{\mathrm{ii}}(\mathrm{t})\right]\right\} \\
\sigma_{\text {Hmax }} & =\max _{\mathrm{t}}\left[\sigma_{\mathrm{ii}}(t)\right]
\end{aligned}
$$

are the mean hydrostatic stress and maximum hydrostatic stress, respectively.

We feel this alternate hydrostatic measure $(P)$ is required, since a judgment about the most applicable criterion is unavailable because of a lack of experimental data on metallic composites. In the ONERA model, only the Sines' criterion was considered (i.e., $\zeta=0$ ). Finally, if we assume that the ratios $\omega_{\mathrm{f} \ell} \eta_{\mathrm{f} \ell} \omega_{\mathrm{u}}, \eta_{\mathrm{u}}, \omega_{\mathrm{m}}$, and $\eta_{\mathrm{m}}$, are each equal to one then the isotropic ONERA model is easily recovered with only a slight modification to the coefficient $a$ in equation (10).

\section{Nondimensional Uniaxial Simplification}

In order to conveniently examine the behavior of a variety of composite systems, consider a uniaxial stress state $\sigma$, fibers oriented at an angle $\theta$ from the $x$-axis (i.e., $\mathrm{d}_{\mathrm{i}}=(\cos \theta, \sin \theta, 0)$ in the $\mathrm{x}-\mathrm{y}$ plane $)$, and the introduction of the following dimensionless parameters. Here both the maximum and mean stresses have been normalized relative to the ultimate (or static fracture) stress $\left(\sigma_{\mathrm{u}_{\mathrm{L}}}\right)$ in the fiber direction; that is,

and

$$
\mathrm{S}_{\max }=\frac{\sigma_{\text {max }}}{\sigma_{\mathrm{u}_{\mathrm{L}}}}
$$

$$
\mathbf{S}=\frac{\bar{\sigma}}{\sigma_{{ }_{\mathrm{u}}}}
$$

respectively. Thus, the uniaxial simplification of equations (9) and (10) are

$$
\frac{\mathrm{dD}_{\mathrm{F}}}{\mathrm{dN}}=\left[1-\left(1-\mathrm{D}_{\mathrm{F}}\right)^{\beta+1}\right]^{\alpha}\left(\mathscr{C}_{\mathrm{m}}\right)^{\beta / 2}\left[\frac{\mathrm{S}_{\mathrm{max}}-\bar{S}^{\beta}}{\left(1-\mathrm{D}_{\mathrm{F}}\right)}\right]^{\beta}
$$

and

$$
\alpha=1-a\left\langle\frac{\left[\sqrt{\mathscr{B C}_{f \ell}}\left(S_{\max }-S\right)-1\right]}{\left[1-\sqrt{\mathscr{B} \mathscr{C}_{u}} S_{\max }\right]}\right\rangle
$$

where

$$
\begin{aligned}
& { }^{8 \mathscr{C}_{\mathrm{m}}}=\frac{1}{\mathscr{N}^{2}}\left\{\left(4 \omega_{\mathrm{m}}^{2}-1\right) \mathrm{A}_{1}+\frac{\left(4 \omega_{\mathrm{m}}^{2}-1\right)}{\eta_{\mathrm{m}}^{2}} \mathrm{~A}_{2}+A_{3}\right\} \\
& \mathscr{C}_{\mathrm{f} \ell}=\frac{1}{\mathscr{R}^{2}}\left\{\left(4 \omega_{\mathrm{f} \ell}^{2}-1\right) A_{1}+\frac{\left(4 \omega_{\mathrm{f} \ell}^{2} \ell^{-1}\right)}{\eta_{\mathrm{f} \ell}^{2}} A_{2}+A_{3}\right\} \\
& \mathscr{C B}_{\mathrm{u}}=\left\{\left(4 \omega_{\mathrm{u}}^{2}-1\right) \mathrm{A}_{1}+\frac{\left(4 \omega_{\mathrm{u}}^{2}-1\right)}{\eta_{\mathrm{u}}^{2}} \mathrm{~A}_{2}+\mathrm{A}_{3}\right\}
\end{aligned}
$$




$$
\begin{aligned}
& \mathscr{A}=\frac{\mathrm{M}_{\mathrm{L}}}{\sigma_{\mathrm{u}_{\mathrm{L}}}} \\
& \mathscr{R}=\frac{\sigma_{\mathrm{f} \ell_{\mathrm{L}}}}{\sigma_{\mathrm{u}_{\mathrm{L}}}} \\
& \mathrm{A}_{1}=\frac{1}{3}-\frac{4}{9} \cos ^{2} \theta-\frac{1}{9} \sin ^{2} \theta+\frac{1}{36}\left(2 \cos ^{2} \theta-\sin ^{2} \theta\right)^{2} \\
& \mathrm{~A}_{2}=\frac{4}{9} \cos ^{2} \theta+\frac{1}{9} \sin ^{2} \theta-\frac{1}{9}\left(2 \cos ^{2} \theta-\sin ^{2} \theta\right)^{2} \\
& \mathrm{~A}_{3}=\frac{1}{4}\left(2 \cos ^{2} \theta-\sin ^{2} \theta\right)^{2}
\end{aligned}
$$

Note that $\mathrm{M}_{\mathrm{L}}(\mathrm{P}), \sigma_{\mathrm{f}}(\mathrm{P}), \sigma_{\mathrm{u}_{\mathrm{L}}}(\mathrm{P})$, and the $\omega$ and $\eta$ ratios are independent of $\sigma_{\mathrm{H}}$ since the modification factor cancels. Again, if $\omega_{()}$and $\eta_{()}$are equal to 1 (i.e., the material is isotropic) then equations (17) and (18) become

$$
\text { and } \begin{aligned}
\mathrm{dD}_{\mathrm{F}}=\left[1-\left(1-\mathrm{D}_{\mathrm{F}}\right)^{\beta+1}\right]^{\alpha}\left[\frac{\mathrm{S}_{\mathrm{max}}{ }^{-S}}{\bar{M}_{\mathrm{L}}\left(1-\mathrm{D}_{\mathrm{F}}\right)}\right]^{\beta} \mathrm{dN} \\
\alpha=1-\dot{\mathrm{a}} \frac{\left\langle\mathrm{S}_{\max }-\mathrm{S}_{\mathrm{f} \ell}(\mathrm{S})\right\rangle}{\left\langle\mathrm{S}_{\mathrm{u}}-\mathrm{S}_{\max }\right\rangle}
\end{aligned}
$$

with $\quad \mathrm{s}_{\mathrm{f} \ell}(\mathrm{S})=\mathrm{s}_{\mathrm{f} \ell}(0)+\left[1-\mathrm{b} \mathrm{s}_{\mathrm{f} \ell}(0)\right] \mathrm{S}$

and

$$
\hat{a}=a\left[\frac{1}{s_{f \ell}}\right]
$$

which is identical in form to the uniaxial ONERA model I (see [29]).

Integrating equation (17) for $N$ cycles, where $S_{\max }$ and $S$ are held fixed, leads to

$$
N=\frac{\left[1-\left(1-D_{F}\right)^{\beta+1}\right]^{(1-\alpha)}}{(1+\beta)}\left[\sqrt{\mathscr{C E}_{m}}\left(S_{\max }-\bar{S}\right)\right]^{-\beta}
$$

By cycling the material to failure $\left(\mathrm{N}_{\mathrm{F}}\right)$, which is defined to occur when $\mathrm{D}_{\mathrm{F}}=1$, we find that

$$
\mathrm{N}_{\mathrm{F}}=\frac{1}{(1+\beta)(1-\alpha)}\left[\sqrt{88_{\mathrm{m}}}\left(\mathrm{S}_{\max }-\mathrm{S}\right)\right]^{-\beta}
$$


or

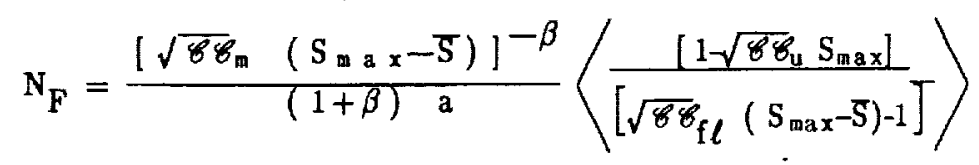

An expression describing the accumulation of damage (for a given loading cycle) in terms of the remaining life ratio can be obtained by substituting equation (25) into equation (24) and rewriting the resulting equation:

$$
D_{F}=1-\left[1-\left(N / N_{F}\right)^{1 /(1-\alpha)}\right] 1 /(1+\beta)
$$

Note that the accumulation of damage is nonlinear and is also a function of fiber orientation, as is the number of cycles to failure.

Similarly, if a two-level loading test is considered, one obtains, by integrating equation (17) in two steps, the same expression as in the case of isotropic materials:

$$
\mathrm{N}_{2} / \mathrm{N}_{\mathrm{F}_{2}}=1-\left(\mathrm{N}_{1} / \mathrm{N}_{\mathrm{F}_{1}}\right)^{\mathrm{p}}, \quad \mathrm{p}=\left(1-\alpha_{2}\right) /\left(1-\alpha_{1}\right)
$$

Here, though $\alpha_{1}, \alpha_{2}, N_{F_{1}}$, and $N_{F_{2}}$ all depend on the orientation of the fibers (or conversely the load). Note that $\mathrm{N}_{\mathrm{F}_{1}}$ and $\mathrm{N}_{\mathrm{F}_{2}}$ are the failure lives (on the $\mathrm{S}-\mathrm{N}$ curve) for the first and second loading conditions, respectively; whereas $\mathrm{N}_{1}$ is the number of cycles applied at the first loading level and $\mathrm{N}_{2}$ is the remaining life at the second level.

\section{RESULTS: PARAMETRIC STUDY}

\section{Direction Independent Parameters}

For an isotropic material (i.e., $w_{0}=\eta_{0}=1$ ) the effect on the S-N curve of varying the parameters $\mathscr{A}, \mathscr{H}, \beta, a$, and the mean stress (S) was examined, see reference [29]. To simplify and yet not limit the study, the parameters $\sigma_{f \ell}$ and $M_{L}$ were taken to be independent of hydrostatic stress; that is to say, b and b' (given in equations (11) and (12)) are zero. The isotropic baseline values assumed were those corresponding to 304 stainless steel [12] (see Table 1). Because material isotropy was assumed, equation (26) becomes

$$
\mathrm{N}_{\mathrm{F}}=\frac{1}{(1+\beta) \mathrm{a}}\left[\frac{\mathrm{S}_{\mathrm{max}}-\mathrm{S}}{\mathscr{H}}\right]^{-\beta}\left\langle\frac{\left[1-\mathrm{S}_{\max }\right] \Re}{\left[S_{\max }-(\mathrm{S}+\Re)\right]}\right\rangle
$$

Equation (29) suggests that if either the mean stress $(S)$ or fatigue ratio $(\Omega)$ are modified, the load level at which an endurance limit is reached is also changed; that is, as either value is increased so is the endurance level. Furthermore, equation (29) indicates that translation of the $\mathrm{S}-\mathrm{N}$ curve can be achieved by varying the parameters $\mathscr{K}$ and a. Increasing $\mathscr{K}$ has been shown (see [29]) to shift the $\mathrm{S}-\mathrm{N}$ curve to the right (increase the number of cycles to failure at a given load), whereas increasing a shified the $\mathrm{S}-\mathrm{N}$ curve to the left (decreased the number of cycles to failure at a given load).

Thus only the product $\left(a \mathcal{K}^{-\beta}\right)$, not the individual values of a and $\mathscr{H}$ is important in determining the life at a given load level. However, the actual value of a does strongly affect the damage accumulation, and therefore if any other type of damage (e.g. creep) is present, both parameters $\mathscr{M}$ and a need to be determined explicitly. 
Table 1 : Dimensionless Parameters for Isotropic and Anisotropic Materials

$\begin{array}{cccc}\text { Parameters } & \begin{array}{c}\text { Values for Baseline } \\ \text { Transversely Isotropic }\end{array} & \begin{array}{c}\text { Values for } \\ \text { SiC/Ti } 15-3\end{array} & \begin{array}{c}\text { Values for } \\ \text { Ti } 15-3\end{array} \\ \Re & 0.25 & 0.18 & 0.16 \\ \mathscr{A} & 4.5 & 14.42 & 7.03 \\ \beta & 3.0 & 1.842 & 2.27 \\ \mathrm{a} & 0.1 & 0.065 & 0.230 \\ S & 0.0 & \mathrm{~S} / 2 & \mathrm{~S} / 2 \\ \omega_{\mathrm{m}} & 5.0 & 11.8 & 1.0 \\ \omega_{\mathrm{fl}} & 5.0 & 12.482 & 1.0 \\ \omega_{\mathrm{u}} & 5.0 & 5.5 & 1.0 \\ \eta_{\mathrm{m}} & 2.0 & 1.0 & 1.0 \\ \eta_{\mathrm{fl}} & 2.0 & 1.0 & 1.0 \\ \eta_{\mathrm{u}} & 2.0 & 1.0 & 1.0 \\ \sigma_{\mathrm{u}} & & 225 . & 128 .\end{array}$

Finally, from equation (29) one can deduce that perturbations in the parameter $\beta$ will both translate the S-N curve and affect the abruptness of the transition from infinite life to immediate failure. Clearly, $\beta=0$ is the lower limit and will give the most abrupt S-N curve for a fixed set of material parameters [29].

\section{Parameters Defining Initial Transverse Isotropy}

Assuming the baseline transversely isotropic material parameters given in Table 1, we examine the modification of the S-N curve with fiber orientation (or equivalently, load orientation relative to a fixed fiber orientation, see Fig. 4). As might be expected (since a composite material is designed to be stronger when loaded parallel to the fiber direction), both the static fracture strength and fatigue limit decreased with an increase in the fiber orientation angle. The reduction in load-carrying ability is clearly dependent on the "degree" of anisotropy and is represented in this fatigue damage model by the $\omega$ and $\eta$ ratios in the ultimate stress $\left(\mathscr{C B}_{\mathrm{u}}\right)$, fatigue limit $\left(\mathbb{B}_{\mathrm{f} \ell}\right)$ and normalizing

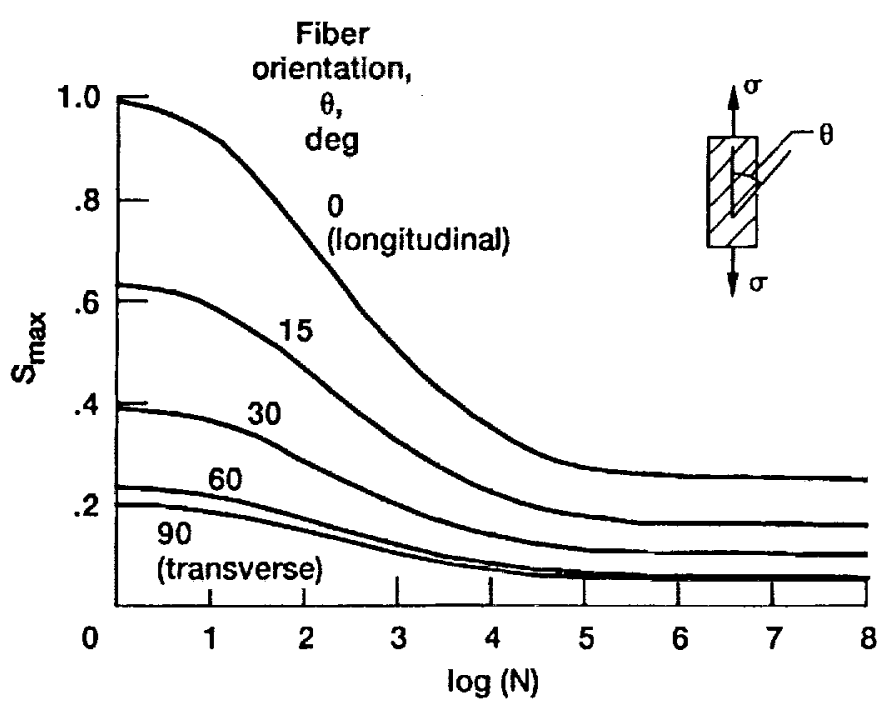

Figure 4.- Illustration of the degradation in load-life response with variation in fiber orientation $\theta$. 
stress amplitude $\left(\mathbb{8}_{\mathrm{m}}\right)$ (see Eq. (26)). Here, with the given baseline material parameter set, all three anisotropic functions are considered to have the same degree of initial anisotropy. In this section an examination of the impact of perturbing the various anisotropic measures will be undertaken.

Equations (19) to (21) and (26) indicate that the angle dependency is manifested through the functions $A_{1}, A_{2}$, and $A_{3}$, which are associated with the longitudinal shear, transverse shear, and normal stress components, respectively. This angle dependency is clearly shown in Fig. 5. Furthermore, Fig. 5 indicates that when $\theta=0^{\circ}$, any changes in the measures of anisotropy (i.e., $\omega$ or $\eta$ ) will have no effect; this suggests that initial characterization of material parameters $a, b, \beta, R$ and $\mathcal{t h}$ as discussed in [29], be conducted with longitudinally reinforced and loaded specimens. Similarly, when $0=90^{\circ}$, any change in the shear "strength" measures (i.e., $\eta_{u^{\prime}}, \eta_{f \ell}$ and $\eta_{m}$ ) will not have any impact in the resulting S-N curves; this suggests that independent evaluation of the $\omega_{u}$ ' $\omega_{\mathrm{f} \ell}$ and $\omega_{\mathrm{m}}$ can be achieved by comparing the longitudinal and transverse specimen response.

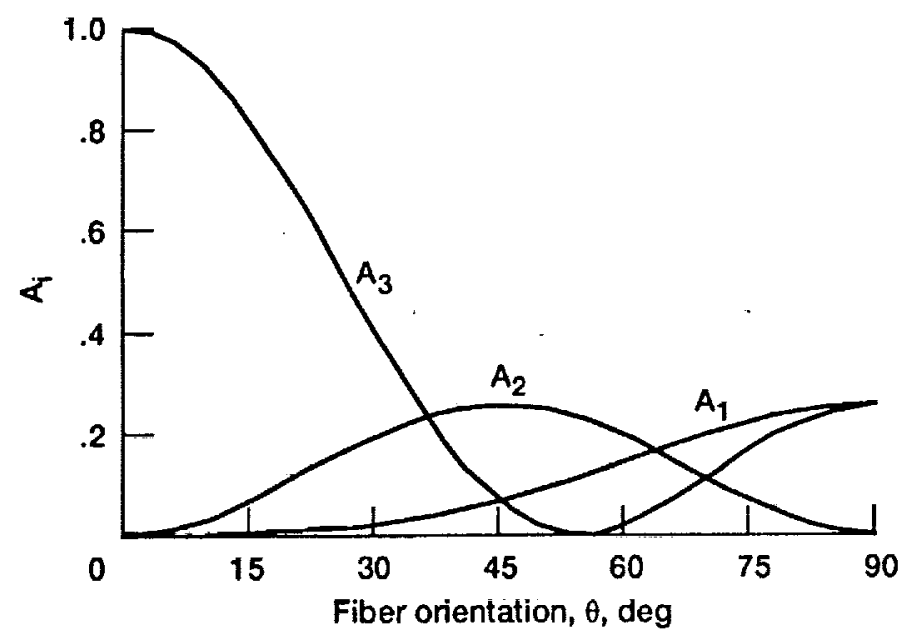

Figure 5.-The angle dependency of the longitudinal shear $\left(A_{1}\right)$, transverse shear $\left(A_{2}\right)$ and normal stress $\left(A_{3}\right)$ components.

\section{Variation of $\omega_{\mathrm{u}}, \omega_{\mathrm{f} \ell}$ and $\omega_{\mathrm{m}}$}

Figure 6 illustrates the effect on the S-N curve (corresponding to a fiber orientation of $\left.\theta=15^{\circ}\right)$ of varying the ultimate strength ratio $\left(\omega_{\mathrm{u}}=\sigma_{\mathrm{u}_{\mathrm{L}}} / \sigma_{\mathrm{u}_{\mathrm{T}}}\right)$. The values of $\omega_{\mathfrak{u}}$ are taken to be $2,4,8$, and 16 , while all other parameters are held fixed at the baseline values given in Table 1. As might be expected increasing the ultimate strength ratio affects only the low cycle fatigue portion of the curve (by decreasing the static fracture stress); the endurance limit remains unaffected. Conversely, increasing the fatigue limit ratio (i.e., $\omega_{\mathrm{f} \ell}=2,4,8$, and 16) and holding all other parameters fixed, as shown in Fig. 7 , decreases the endurance limit and leaves the ultimate strength unchanged. Note, that although the present model provides significant flexibility, in that $\omega_{u}$ and $\omega_{f l}$ can be varied independently, in reality a relationship between the ultimate strength and the endurance limit would be expected, thus placing restrictions on the ranges of these parameters. 


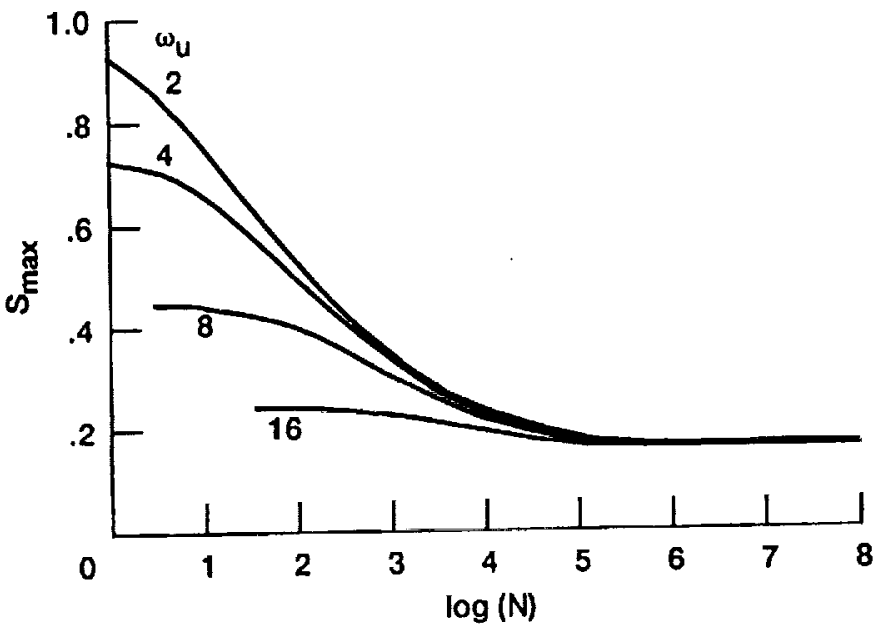

Figure 6.-Effect on the S-N curve of varying the ratio $\omega_{y}$ at an angle of $15^{\circ}$ while holding all other parameters fixed at the baseline values.

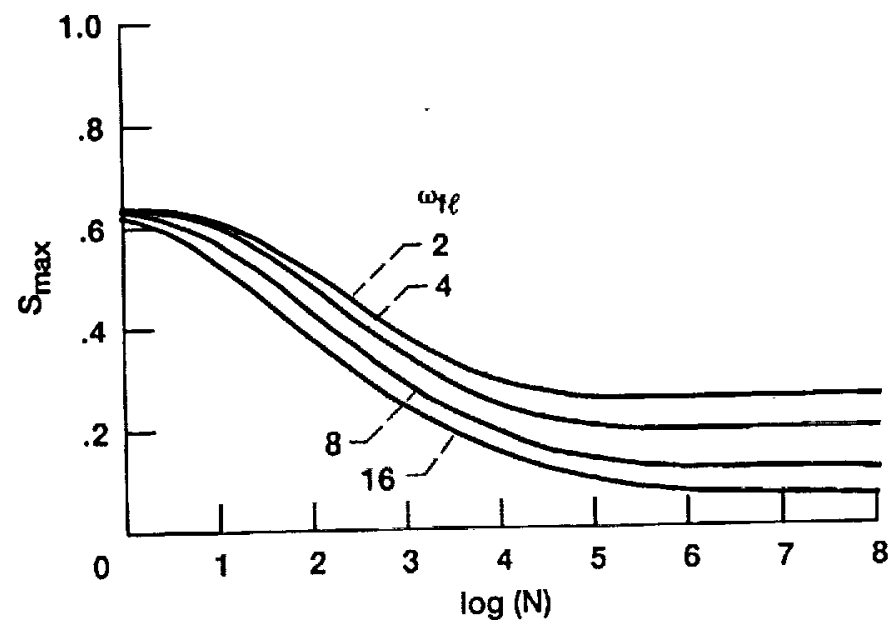

Figure 7.-Effect on the S-N curve of varying the ratio $\omega_{\mathrm{f} \ell}$ at an angle of $15^{\circ}$ while holding all other parameters fixed at the baseline values. 
By varying the normalizing stress ratio $\omega_{m}$, a horizontal translation of the transition portion of the $\mathrm{S}-\mathrm{N}$ curve can be obtained while the ultimate stress and fatigue limit remain unchanged. An example is shown in Fig. 8, where $\omega_{\mathrm{m}}$ takes on the values of $2,4,8$, and 16 , the fiber orientation is $1^{\circ}$, and all other parameters again remain fixed. Clearly, increasing the ratio shifts the S-N curve to the left thereby decreasing the number of cycles to failure for a given load. Thus, by merely assuming different

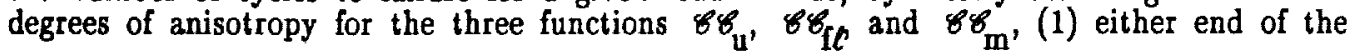
S-N curve can be modified while the other end remains unchanged, or (2) the center portion can be horizontally translated, while the ultimate and fatigue limit stresses remain unchanged. This suggests that the model has sufficient flexibility to fit a broad class of materials.

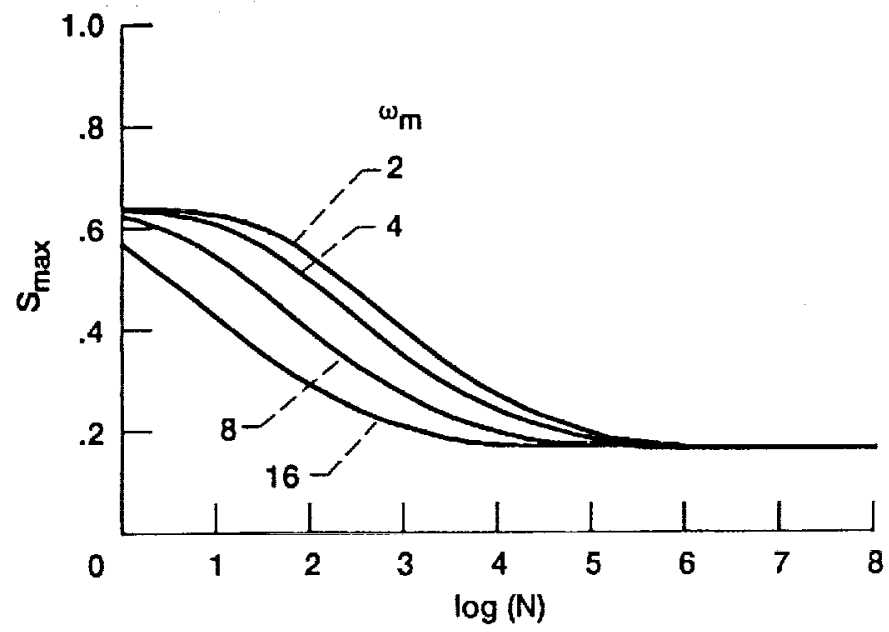

Figure 8.--Effect on the S-N curve of varying the ratio $\omega_{\mathrm{m}}$ at an angle of $15^{\circ}$ while holding all other parameters fixed at the baseline values.

The impact on the S-N curve of varying the degree of anisotropy, for example $\omega_{u}$, can be seen for all fiber orientation angles by plotting the functions $\sqrt{\mathscr{B} \mathscr{C}_{\mathrm{f}} \ell}, \sqrt{\mathscr{C}^{\mathscr{B}} \mathrm{u}}$, and $\sqrt{8 \mathscr{C}_{\mathrm{m}}}$. In Fig. 9 only $\sqrt{\mathscr{8} \mathscr{C}_{\mathrm{u}}}$ is shown versus angle of orientation $\theta$, since the other two functions behave similarly, except for being scaled by a multiplying factor. It is evident in Fig. 9 that for a specified ratio $\omega_{u}$ the function $\sqrt{\mathscr{B} \mathbb{C}_{u}}$ increases as the angle $\theta$ increases; however, there is an angle, depending upon the magnitude of $\omega_{u}$, at which this rate of increase decreases. This explains the incrementally smaller changes in the response curve with increasingly larger angles (i.e., variation in the $S-N$ curve, see Fig. 4). Finally, another important point that can be discerned from Fig. 9, is the need for $\omega$ to always be greater than or equal to $\eta$, since if $\omega<\eta$, a minimum occurs in the function at an angle other than zero, which violates physical reasoning. 


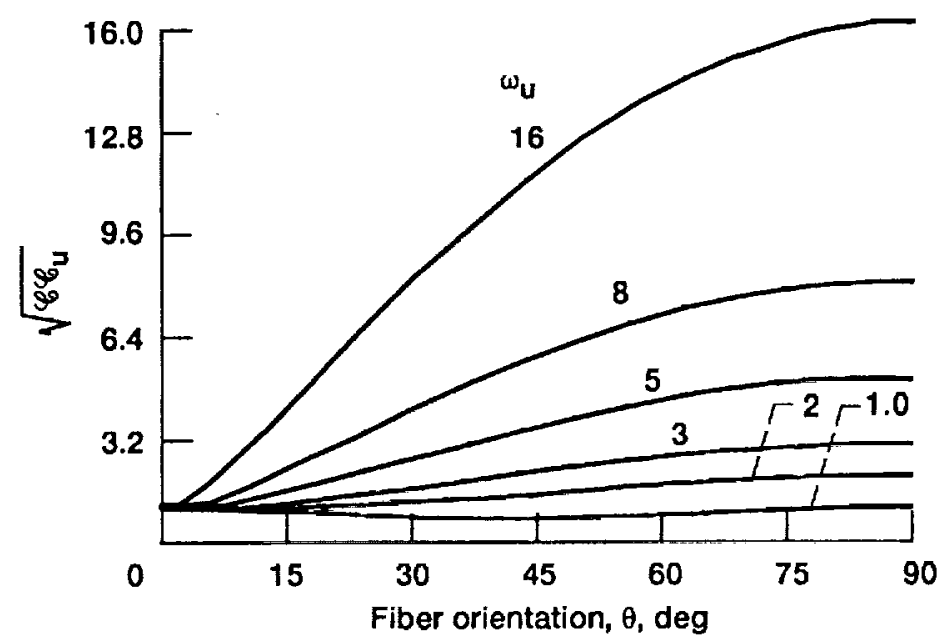

Figure 9.-Impact of varying $\omega_{u}$ when $\eta_{u}=2.0$ and all other parameters are those in Table I.

Variation of $\eta_{\mathbf{u}^{2}} \eta_{\mathfrak{f} \ell^{2}}$ and $\eta_{\mathrm{m}}$

Variation of the shear ratios $\eta_{\mathrm{u}}, \eta_{\mathrm{f} \ell}$ and $\eta_{\mathrm{m}}$ has an impact on the overall trends, but not actual magnitudes, of the $\mathrm{S}-\mathrm{N}$ curve, similar to variations in the respective normal stress ratios. Examples involving the variations of each ratio are given in [29]. The interaction between the shear strength and the normal strength ratio is shown in Fig. 10, for $\omega_{\mathrm{u}}=5.0$, and $\eta_{\mathrm{u}}=1,1.5,2,3,4$, and 5 ; and in Fig. 11, for $\omega_{\mathrm{u}}=16.0$ and $\eta_{u}=1.0,1.5,2,4,8$, and 16 . Note how in both figures the shape of the function ${ }^{8} \mathscr{8}_{\mathrm{u}}$ is greatly affected, particularly for low values of $\eta$. Also it is clear that when $\eta=$ 1 , a maximum at some intermediate angle is obtained. The ramification of this intermediate maximum is unknown at this time. As with the cases involving the normal stress ratios $\omega_{\mathrm{u}}$ and $\omega_{\mathrm{f} \ell}$, one would expect a relationship to exist between $\eta_{\mathrm{u}}$ and $\eta_{\mathfrak{f} \ell}$ such that the practical ranges of these parameters are not independent.

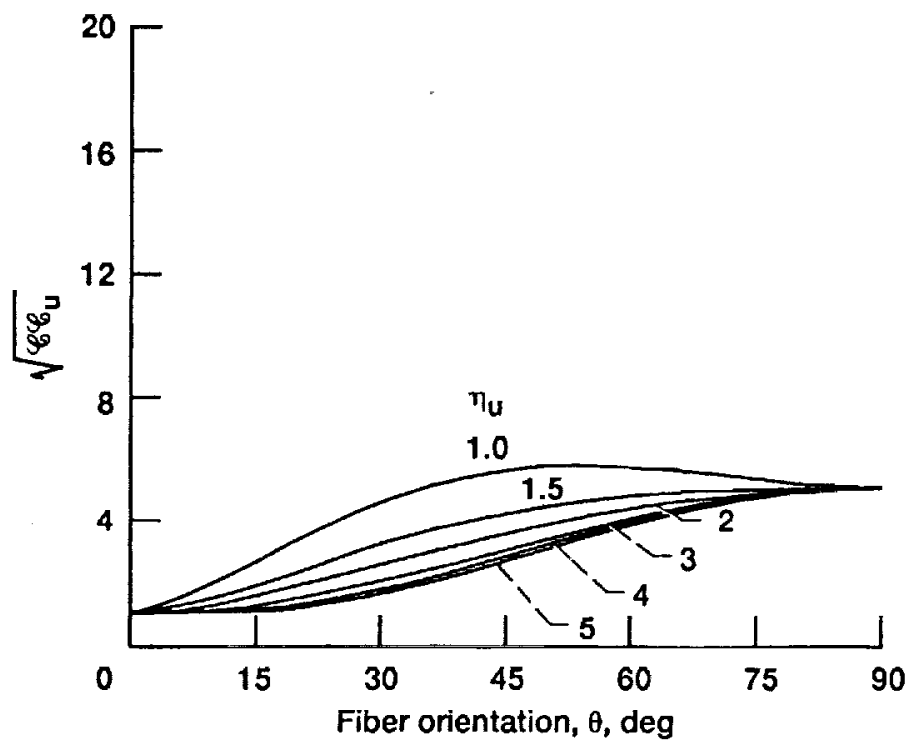

Figure 10.-Impact of varying $\eta_{u}$ when $\omega_{u}=5.0$ and all other parameters are those in Table I. 


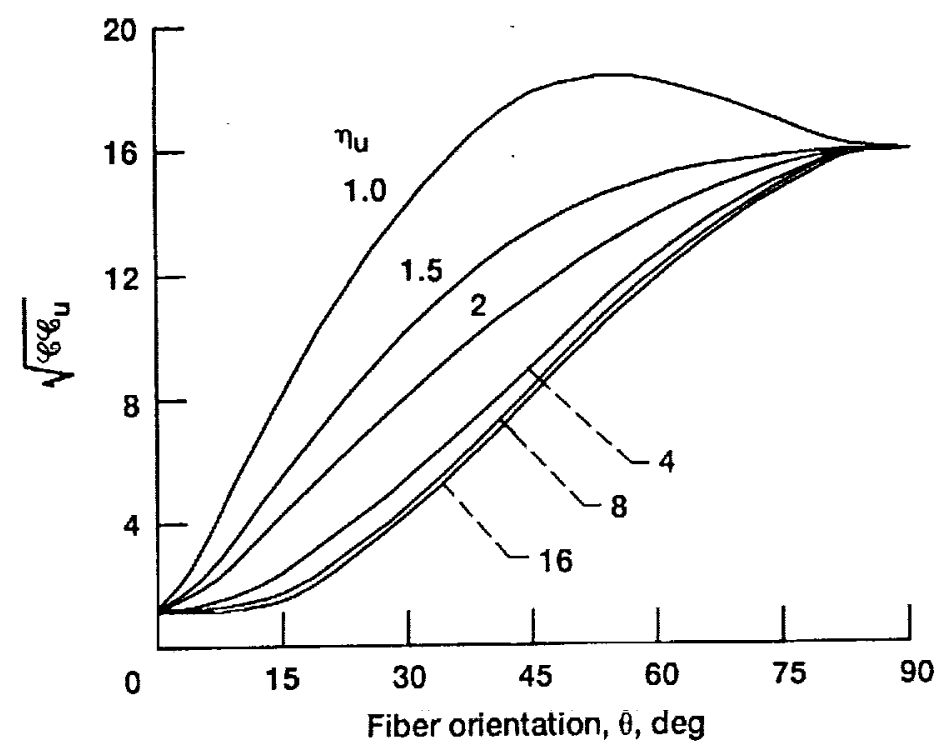

Figure 11. - Impact of varying $\eta_{u}$ when $\omega_{u}=16.0$ and all other parameters are those in Table I.

\section{CHARACTERIZATION EXPERIMENTS}

The required exploration and characterization experiments for the present model are completely described in [29]. Here, we want to briefly touch on the testing required, both in tension and torsion in the longitudinal and transverse directions, to define the extent of initial anisotropy (i.e., the ratios $\omega_{u}, \eta_{u}, \omega_{f \ell} \eta_{\mathrm{f} \ell} \omega_{\mathrm{m}}$, and $\eta_{\mathrm{m}}$ ) of a

hexagonally packed unidirectional composite material. Figure 12 illustrates schematically the expected S-N curves for a composite material loaded longitudinally $\left(\theta=0^{\circ}\right)$ and transversely $\left(\theta=90^{\circ}\right)$ at a given mean stress. From such data, as well as the associated shear $\mathrm{S}-\mathrm{N}$ curves, the various $\omega$ and $\eta$ ratios can be determined. Note that in the present theory, $\beta, a$, and $b$ are assumed to be independent of fiber orientation (i.e., $d_{\mathfrak{i}}$ ). This assumption may need to be modified if experimental evidence suggests otherwise.

Clearly, the four S-N curves (Fig. 12, repeated once for tension and once for shear) as well as other experiments discussed in [29] suggest a significant, and potentially quite expensive, experimental program. This experimental program may, however, be able to be reduced and augmented through numerical simulation by using a suitable homogenization technique with periodic boundary conditions. Furthermore, utilization of a homogenization technique should allow micromechanical effects (e.g., bond strength, volume fraction, etc.) to be included in this phenomenological theory, through the parameters $\sigma_{\mathrm{u}_{\mathrm{L}}}, \sigma_{\mathrm{f} \ell_{\mathrm{L}}}, \omega_{\mathrm{u}}, \eta_{\mathrm{u}}, \omega_{\mathrm{f} \ell}$ and $\eta_{\mathrm{f} \ell}$

Recently, a model metal matrix composite system (i.e., SiC/Ti 15-3) and matrix material (i.e., $\mathrm{Ti} 15-3$ ) were used in the correlation of the present fatigue CDM model. Figure 13 shows both the correlations (lines) and the experimental data (symbols) for a 35 fiber \%, longitudinal and transverse composite and the Ti 15-3 matrix material at $427^{\circ} \mathrm{C}$. Table 1 lists the specific individual material parameters used. As suggested earlier, the longitudinal response was used to obtain the constants $a, \beta, M_{L}, \sigma_{u_{L}}$, and

$\sigma_{\mathrm{fl}}$. Then while these constants were held fixed, the three transverse data points were fit to obtain the "strengths" of anisotropy, $\omega_{\mathrm{u}}, \omega_{\mathrm{f} \ell}$, and $\omega_{\mathrm{m}}$. Note that the shear ratios, $\eta_{\mathrm{u}}, \eta_{\mathrm{f} \ell}$ and $\eta_{\mathrm{m}}$ were all assumed to be 1.0 (i.e., isotropic in shear) and the 
effect of mean stress on the fatigue limit and stress amplitude (M) was neglected (i.e., $b=0$ ) because of the lack of data. Finally, in Fig. 13, the solid square symbol associated with the $90^{\circ}$ response was not used in the correlation data set for the composite response and therefore represents a check on the predictive capability of the present model at the coupon level. The accuracy is within a factor of 2.

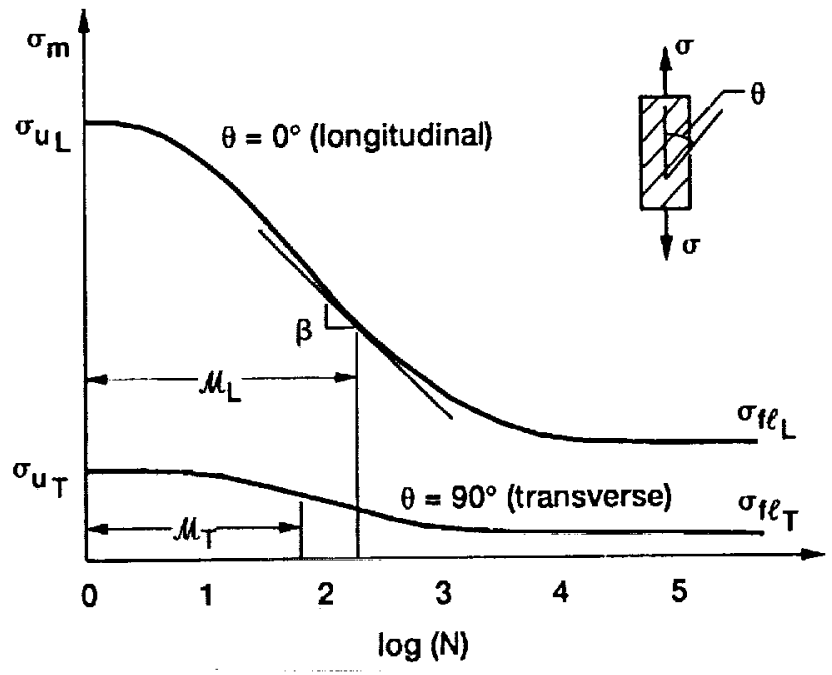

Figure 12.-Expected S-N curves for a unidirectional metallic composite loaded longitudinally $(\theta=0)$ and transversely $(\theta=90)$.

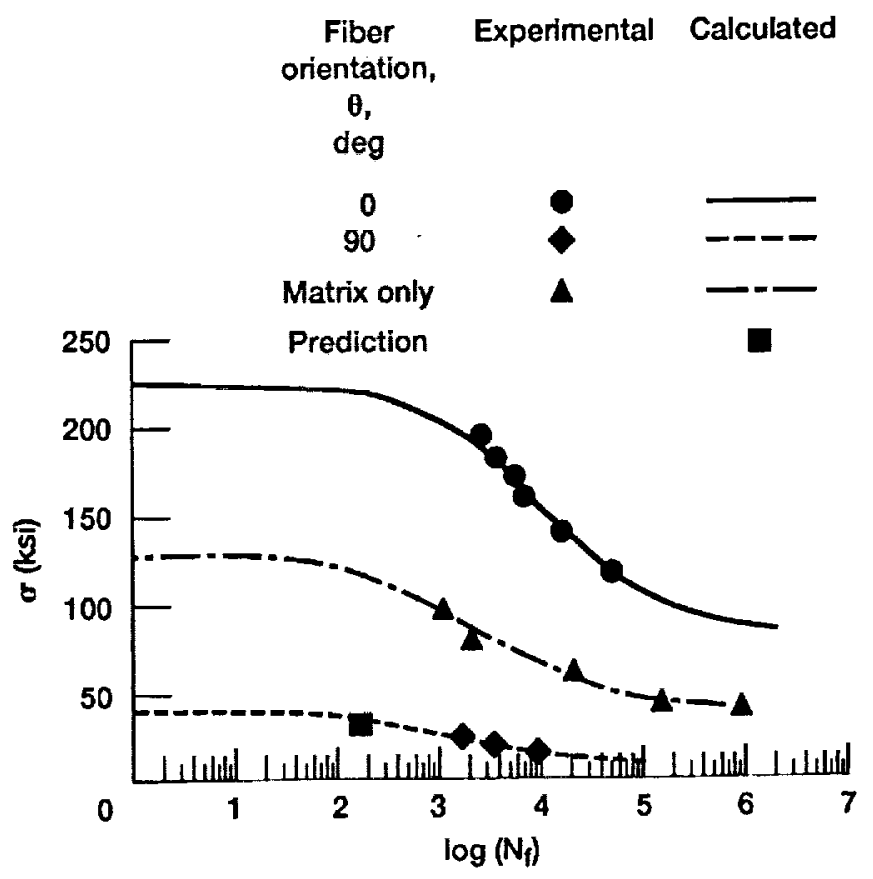

Figure 13.-Correlation of CDM model with SiC/Ti-15-3 composite and Ti-15-3 matrix coupon data. 


\section{CONCLUSIONS}

An isothermal, multiaxial, continuum damage mechanics model for fatigue of a unidirectional metal matrix composite volume element has been presented. The intended applications are reinforced structures in which the fiber direction may vary throughout but in which a single fiber direction can be identified locally (local transverse isotropy) within a given volume element. The model is phenomenological, stress based, and assumes a single scalar internal damage variable, whose evolution is anisotropic and is associated with the initiation and propagation of transgranular defects.

The development of this model (i.e., the fatigue damage evolutionary law) is founded on the definition of an initially transversely isotropic fatigue limit surface, static fracture surface and a normalized stress amplitude function. The anisotropy of the model is defined through physically meaningful invariants reflecting the local stress and material orientation. The model has been shown, when taken to its isotropic limit, to directly simplify to a previously developed and validated fatigue continuum damage model.

Results of a nondimensional parametric study illustrate (1) the flexibility of the present formulation in attempts to characterize a large class of composite materials and (2) the ability of the formulation to predict anticipated qualitative trends in the fatigue behavior of unidirectional metal matrix composites. Additionally, an example correlation of a metal matrix composite system (i.e., $\mathrm{SiC} / \mathrm{Ti} 15-3$ ) and metal matrix material (i.e., Ti 15-3) was shown.

Two potential drawbacks to the present formulation are (1) the scalar damage measure employed and (2) the potentially expensive experimental program required. Future work in this area will include an examination of the present formulation's usefulness in predicting the fatigue life of high-temperature applications; initiation of an experimental characterization and validation program; and the numerical implementation into a post processing life prediction computer code.

\section{ACKNOWLEDGMENTS}

This work was primarily completed during the first author's tenure at ONERA, while participating in a NASA/ONERA exchange program. Both authors are grateful to J.L. Chaboche, M. Chaudonneret, P.M. Lesne, and S. Savalle for the many long and fruitful discussions regarding the ONERA CDM models and for their encouragement and interest in this work.

\section{REFERENCES}

1) Eshelby, J. D., "The Determination of the Elastic Field of an Ellipsoidal Inclusion and Related Problems", Proc. R. Soc. A241, 1957, pp. 376-396.

2) Mura, T., Micromechanics of Defects in Solids, M. Nijhoff, The Hague, The Netherlands, 1982.

3) Budiansky, B., "Micromechanics II," Proc. 10th U.S. National Congress of Applied Mechanics, J.P. Lamb, ed. ASME, New York, 1987, pp. 25-32.

4) Krajcinovic, D. and Sumarac, D., "Micromechanically Based Damage Models", Proc. 10th U.S. National Congress of Applied Mechanics, J.P. Lamb, ed. , ASME, New York, 1987, pp. 115-123.

5) Nemat-Nasser, S., "Micromechnically Based Constitutive Modeling of Inelastic Response of Solids," Constitutive Models of Deformation, J. Chandra and R.P. Srlivastava, eds., SIAM, Philadelphia, PA, 1987, pp. 120-129.

6) Sanchez-Palenzia, E., and Zaoui, A., Homogenization Techniques for Composite Media, Springer, New York, 1987.

7) Kachanov, L.M., Introduction to Continuum Damage Mechanics, Martinus Nijhoff, Dordrecht, The Netherlands, 1986 .

8) Leckie, F.A., and Hayhurst, D.R.,"Creep Rupture in Structures", Proc. R. Soc. Lond., Vol. $340 \mathrm{~A}, 1974$, pp 323-347.

9) Janson, J., "A Continuum Damage Approach to the Fatigue Process", Eng. Fract. Mech., Vol. 10, 1978, pp. 651-657. 
10) Chaboche, J.L., and Lesne, P.M., "A Non-Linear Continuous Fatigue Damage Model", Fatigue Fract. Engng. Mater. Struct., Vol. 11, No. 1., 1988, pp.1-7.

11) Chaboche, J.L., "Phenomenological Aspects of Continuum Damage Mechanics", Materials and Engineering Design : The Next Decade, B.F. Dyson and D.P. Hayhurst, eds., Institute of Metals, Brookfield, Vt, 1989, pp. 352-365.

12) Lemaitre, J., and Chaboche, J.L., Mechanics of Solid Materials, Cambridge University Press, Cambridge, MA.,1990.

13) Hayhurst D.R., "Creep Rupture Under Multiaxial State of Stress", J. Mech. Phys. Solids, Vol. 20, No. 6, 1972, pp. 381-390.

14) Krajcinovic, D., and Fonseka, G.U., "The Continuous Damage Mechanics of Brittle Materials - Parts I and II", J. Appl. Mech., Vol. 48, No. 4, 1981, pp. 809-815.

15) Talreja, R., "A Continuum Mechanics Characterization of Damage in Composite Material", Proc. R. Soc. Lond., Vol. A399, 1985, pp. 195-216.

16) Leckie, F.A., and Onat, E.T., "Tensorial Nature of Damage Measuring Internal Variables", IUTAM Symp. on Physical Non-Linearities in Structural Analysis, J. A. Hult and J. Lemaitre, eds., Springer, New York, 1980, pp. 140-155.

17) Murakami, S., and Ohno, N., "A Continuum Theory of Creep and Creep Damage", Creep in Structures, A.R.S. Ponter, ed. Springer, New York, pp. 422-453.

18) Chaboche J.L. "Continuum Damage Mechanics : Part I - General Concepts", J. Appl. Mech., Vol. 55, No. 3, 1988, pp. 59-64.

19) Chaboche J.L., "Continuum Damage Mechanics : Part II - Damage Growth, Crack Initiation and Crack Growth", J. Appl. Mech., Vol. 55, No. 3, 1988, pp. 65-72.

20) Krajcinovic, D., "Continuum Damage Mechanics", Appl. Mech. Reviews, Vol. 37, No. 1, 1984, pp. 1-6.

21) Krajcinovic, D., "Damage Mechanics", Mech. of Materials, Vol. 8, 1989, pp. $117-197$.

22) Hult, J.,"Continuum Damage Mechanics (CDM) - A New Design Tool," Materials and Engineering Design: The Next Decade, B.F. Dyson, and D.R. Hayhurst, eds, Institute of Metals, Brookfield, VT, 1989, pp. 199-204.

23) Rabotnov, Y.N., Creep Problems in Structural Members, North Holland, Amsterdam, 1969.

24) Rabier, P.J., "Some Remarks on Damage Theory", Int. J. Engng. Sci.,Vol. 27, No. 1, 1989, pp. 29-54.

25) Lesne, P.M., and Savalle, S. "A Differential Damage Rule with Microinitiation and Micropropagation", Rech. Aerosp., No. 2, 1987, pp. 33-47.

26) Lesne, P.M., and Cailletaud, G., "Creep-Fatigue Interaction Under High Frequency Loading", 5th Int. Conf. in Mechanical Behavior of Materials, Beijing, China, ONERA TP $1987-66,1987$.

27) Chaboche, J.L., "Fracture Mechanics and Damage Mechanics : Complementary of Approaches", Int. Conf. on Numerical Methods in Fracture Mechanics, San Antonio, TX, Pineridge Press, ONERA TP 1987-25 1987, pp. 308-324.

28) Chaboche, J.L., "Continuous Damage Mechanics - Tool to Describe Phenomena Before Crack Initiation," Nuclear Engineering and Design, Vol. 64, 1981, pp. 233-247.

29) Arnold, S.M., and Kruch, S., "Differential Continuum Damage Mechanics Models for Creep and Fatigue of Unidirectional Metal Matrix Composites," NASA TM-105213, 1991.

30) Cailletaud, 'G., and Levaillant, C., "Creep-Fatigue Life Prediction : What about Initiation ?", Nucl. Engng. Design., Vol. 83, 1984, pp. 279-292.

31) Hua, C.T., and Socie, D.F., "Fatigue Damage in 1045 Steel Under Constant Amplitude Biaxial Loading", Fatigue Engng. Mater. Struct., Vol. 7, No. 3, 1984, pp. $165-179$.

32) Socie, D.F., Fash, J.W., and Leckie, F.A., "A Continuum Damage Model For Fatigue Analysis of Cast Iron", ASME, Conf. in Life Prediction,D. A. Woodford and J.R. Whitehead, eds., ASME, New York,pp. 59-64, 1983.

33) Gabb, T.P., Gayda, J. and Mackay, R.A.,"Nonisothermal Fatigue Degradation of Sic/Ti Composite", Ceramic Transactions, Vol. 19, 1991, pp. 527-534.

34) Verrilli, M., Fatigue and Fracture Branch, NASA Lewis Research Center, Cleveland, OH, Private communication, 1991. 
35) Gayda, J., Gabb, T.P., and Lerch, B.A., "The Effects of Environment on The Fatigue Life of SiC/Ti-15-3 Composites", Presented at the 6th TMF Workshop, NASA Lewis Research Center, Cleveland, OH, 1991.

36) Talreja, R., Fatigue of Composite Materials, Technomic Pub., Lancaster, PA, 1987.

37) Robinson, D. N., Binienda, W.K., and Miti-Kavuma,M., "Creep and Creep Rupture of Strongly Reinforced Metallic Composites", NASA CR-185286, 1990.

38) Grobstein, T.L., "The Interface in Tungsten Fiber Reinforced Niobium Metal-Matrix Composites", NASA TM-102122, 1989.

39) Robinson, D.N., and Duffy, S.F., "Continuum Deformation Theory for High Temperature Metallic Composites", J. Engng. Mech., Vol. 16, No. 4, 1990, pp. 832-844.

40) Bartolotta, P., "Fatigue Life Prediction of an Intermetallic Matrix Composite at Elevated Temperature," NASA TM-104494, 1991.

41) Arnold, S.M., "A Transversely Isotropic Thermoelastic Theory," NASA TM-101302, 1989.

42) Sines, G., "Behavior of Metals Under Complex Static and Alternating Stresses", Metal Fatigue, G. Sines and J.L. Waisman (eds.), McGraw Hill, New York, 1959, pp. 145-169.

43) Crossland, B., "Effects of Large Hydrostatic Pressures on the Torsional Fatigue Strength of an Alloy Steel," Proceedings, Int. Conf. on Fatigue of Metals, Institute of Mechanical Engineering, London, 1956, pp. 138-145. 
Publc reporting burden for this collection of information is estimated to average 1 hour per response, including the time for reviewing instructions, searching existing data sources, gathering and maintaining the data needed, and completing and reviewing the collection of information. Send comments regarding this burden estimate or any other aspect of this collection of information, including suggestions for reducing this burden, to Washington Headquarters Services. Directorate for information Operations and Reports, 1215 Jefferson Davis Highway, Sutte 1204, Arlington, VA 22202-4302, and to the Office of Management and Budget, Papenwork Reduction Project (0704-0188), Washington, DC 20503.

\begin{tabular}{|l|l|l|}
\hline 1. AGENCY USE ONLY (Leave blank) & $\begin{array}{c}\text { 2. REPORT DATE } \\
\text { November } 1992\end{array}$ & $\begin{array}{c}\text { 3. REPOAT TYPE AND DATES COVERED } \\
\text { Technical Memorandum }\end{array}$ \\
\hline
\end{tabular}

4. TITLE AND SUBTITLE

5. FUNDING NUMBERS

A Differential CDM Model for Fatigue of Unidirectional Metal

Matrix Composites

6. AUTHOR(S)

WU-510-01-50

S.M. Arnold and S. Kruch

7. PERFORMING ORGANIZATION NAME(S) AND ADDRESS(ES)

8. PERForming ORganization REPORT NUMBER

National Aeronautics and Space Administration

Lewis Research Center

E-7128

Cleveland, Ohio 44135-3191

10. SPONSORING/MONITORING AGENCY REPORT NUMBER

National Aeronautics and Space Administration

Washington, D.C. 20546-0001

NASA TM-105726

11. SUPPLEMENTARY NOTES

Prepared for the American Society of Mechanical Engineers, Anaheim, California, November 8-13, 1992.

S.M. Arnold, NASA Lewis Research Center, and S. Kruch, ONERA, 92322 Chatillon, France. Responsible person, S.M. Arnold, (216) 433-3334.

12a. DISTRIBUTION/AVAILABILITY STATEMENT

12b. DISTRIBUTION CODE

Unclassified - Unlimitcd

Subject Category 39

\section{ABSTRACT (Maximum 200 words)}

A multiaxial, isothermal, continuum damage mechanics model for fatigue of a unidirectional metal matrix composite volume element is presented. The model is phenomenological, stress based, and assumes a single scalar internal damage variable, the evolution of which is anisotropic. The development of the fatigue damage model, (i.e., evolutionary law) is based on the definition of an initially transversely isotropic fatigue limit surface, a static fracture surface, and a normalized stress amplitude function. The anisotropy of these surfaces and function, and therefore the model, is defined through physically meaningful invariants reflecting the local stress and material orientation. This transversely isotropic model is shown, when taken to it's isotropic limit, to directly simplify to a previously developed and validated isotropic fatigue continuum damage model. Results of a nondimensional parametric study illustrate (1) the flexibility of the present formulation in attempting to characterize a class of composite materials and (2) the capability of the formulation in predicting anticipated qualitative trends in the fatigue behavior of unidirectional metal matrix composites. Also, specific material parameters representing an initial characterization of the composite system SiC/Ti 15-3 and the matrix material (Ti 15-3) are reported.

\section{SUBJECT TERMS}

Continuum damage; Fatigue; Metal matrix composites; Damage accumulation 22

17. SECURITY CLASSIFICATION OF REPORT

Unclassified

\section{SECURITY CLASSIFICATION OF THIS PAGE Unclassified}

19. SECURTY CLASSIFICATION OF ABSTRACT Unclassified 